\title{
Lifespan of Snake without Food: a Case Study of Doda, Kashmir, India
}

\author{
Ajaz A. Wani, Imteyaz Ahmed, Muneesh Kumar, \\ Department of Zoology Govt Degree College Doda, University of \\ Jammu, Kashmir, India
}

\section{Introduction:}

Snakes that belong to class Reptilia order Squamata and suborder serpentine are elongated legless carnivores. There are ectodermic amniotes vertebrate covered with overlapping scales. Many species of snakes have a skull with several more joints than their lizard ancestors, which enable them to swallow prey much larger than their heads with their highly mobile jaws, these occupy every type of habitat except Antarctica region. Snakes are thought to have evolved from either burrowing or aquatic lizards perhaps during the Jurassic period with the earliest known fossil dating to 143 to 167 million years ago. The diversity of modern snakes appeared during the Paleocene epoch. The present article deals with the study of how long a snake survives without food. On the 16th of September 2018, we found this snake and identif ied by snake expert as Platyceps ventromaculatus (nonvenomous). .

\section{Our study:}

From the date of collection, the snake was kept under observation in the Zoology Lab inside a glass jar. The lid of the jar was made porous for oxygen supply. In the first month of observation, the snake was active in the glass jar, but during the 2nd half of the 2nd month, it started to become thin and getting sluggish day by day. Finally, by the 79 th day of it in the jar, it died as no movement was observed in the jar. In a study, McCue (2007) reported that snakes withstood 168 days of starvation. In his study, he included three distantly related snake species (i.e., ball python, Python regius; ratsnake, Elaphe obsoleta; and western diamond back rattlesnake, Crotalus atrox). Snakes can lower their metabolic rate by up to $70 \%$ allowing them to survive prolonged periods without food while growing longer nonetheless. Clerk (2006) reported that wild timber rattlesnake (Crotalus horridus) eat 12 to 15 times per season on average about twice per month. This snake lives without food for months. Some temperate area snakes are even well known for undergoing dormancy for five or six months at a time when they do not eat. Cold-blooded animals have very low metabolism though snakes may produce extra metabolic heat when digesting prey. As snakes require less food to fuel their furnaces, they can go long periods without eating.
Study Area: Doda, Kashmir, India

Coordinated: $33^{\circ} 08^{\prime} 45^{\prime \prime N}$; $75^{\circ} 32^{\prime} 52^{\prime \prime} \mathrm{E}$

Key words: Feeding, Non venomous, Starvation

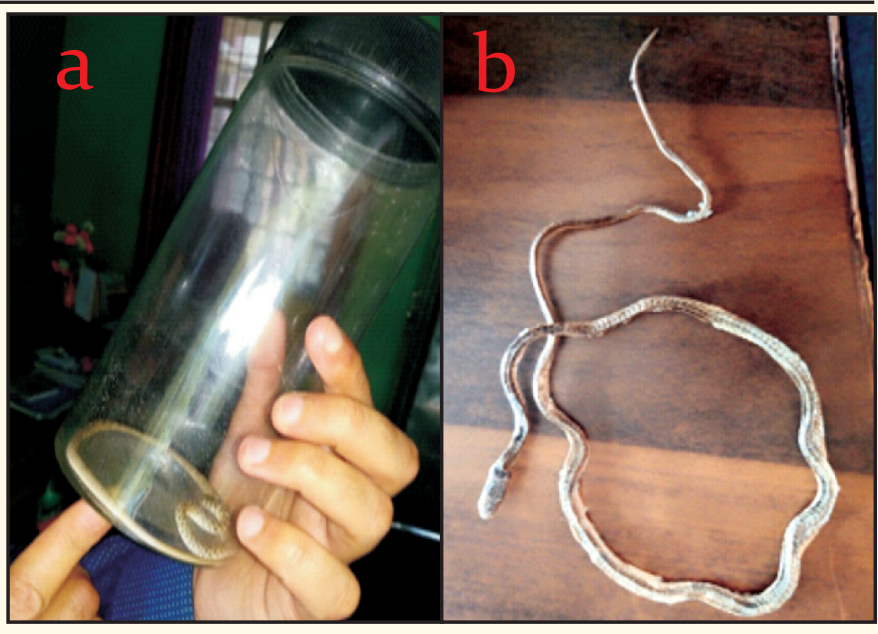

Figure-1: a) Snake inside the jar at initial stage; b) Dead snake after 79 days.

\section{Conclusion:}

It has been reported by Secor \& Diamond (1998) that most of the snake large prey, even more than their own body weight in advance. Sometimes they can also reduce their metabolic rate too to hold energetic constraints (Hulbert \& Else, 1981; McCue, 2007). Infact snakes sometimes follow liberalism in energetic costs of maintaining the digestive tract during periods of fasting (Secor \& Diamond 2000) it is to continue the physiological processes even after long fasting periods.

Acknowledgements:

Prof. D. N. Sahi (Snakes specialist) retired professor of Dept of Zoology of University of Jammu, India for identifying the snake.

\section{References:}

Clark, R.W. (2006): Fixed videography to study predation behavior of an ambush foraging snake, Crotalus horridus. Copeia 2006:181-187

Else, P.L. \& Hulbert, A.J. (1981): Comparison of the "mammal machine" and the "reptile machine": energy production. $\underline{\text { Am. }}$ L.Physiol. Reg., 240(1):R350-R356.

McCue, M.D. (2007): Western diamondback rattlesnakes demonstrate physiological and biochemical strategies for tolerating prolonged starvation. Physiol. Biochem. Zool., 8o:25-34.

Secor, S.M., Stein, E.D. \& Diamond, J. (1994): Rapid upregulation of snake intestine in response to feeding: a new model of 